\title{
Lung cancer in relation to employment in the electrical utility industry and exposure to magnetic fields
}

\author{
David A Savitz, Vincent Dufort, Ben Armstrong, Gilles Thériault
}

\begin{abstract}
Objectives-A recent study found that lung cancer may be associated with exposures encountered in the electrical utility industry. To further evaluate this possibility, data were collected and analysed from five large electrical utility companies in the United States.

Methods-A cohort of 138905 male workers employed between 1950 and 1986 was followed up for mortality to the end of 1988, with 20733 deaths identified of which 1692 were due to lung cancer. Mortality from lung cancer was examined in relation to the duration of employment in specific jobs thought to have high exposure to $60 \mathrm{~Hz}$ magnetic fields and to an index of cumulative exposure to magnetic fields based on personal measurements. Exposure to pulsed electromagnetic fields (PEMFs) as estimated from another study was also considered. Poisson regression generated rate ratios for categories of exposure based on comparisons within the cohort adjusted for age, calendar year, race, socioeconomic status, work status, and estimated exposure to asbestos.
\end{abstract}

Results-Mortality rose modestly with duration of work as an electrician or power plant operator reaching rate ratios of 1.4 with $>20$ years in those jobs but not with duration of work as a lineman or a combination of jobs thought to have high exposures to $60 \mathrm{~Hz}$ magnetic fields or PEMFs. Cumulative indices of exposure to $60 \mathrm{~Hz}$ magnetic fields and PEMFs were both associated with rate ratios of 1.2-1.3 in the highest intervals.

Conclusions-These data suggest that lung cancer is not strongly associated with duration of employment in specific jobs associated with high potential exposure to $60 \mathrm{~Hz}$ magnetic fields or to PEMFs. Small associations of lung cancer with indices of both $60 \mathrm{~Hz}$ magnetic fields and PEMFs leave open the possibility that larger associations have been diluted through exposure misclassification. Refined exposure assessment, especially to PEMFs, would be required to evaluate that possibility.

(Occup Environ Med 1997;54:396-402)

Keywords: electromagnetic fields; lung neoplasms
Occupational studies of electric and magnetic fields related to cancer have mostly focused on leukaemia and brain cancer, with a secondary interest in lymphoma, melanoma, and breast cancer. ${ }^{12}$ However, the recent publication concerning pulsed electromagnetic fields (PEMFs) and cancer among utility workers in Québec, Canada, and France ${ }^{3}$ raised concerns that lung cancer could be a potential consequence of some forms of exposure to electric or magnetic fields encountered in this setting. Given that the incidence of lung cancer exceeds that of leukaemia and brain cancer combined by a factor of around four in men, ${ }^{4}$ any suggestion of an association with occupational exposures in the electrical utility industry warrants careful examination.

The study that stimulated our evaluation attempted to examine extremely short duration spikes of exposure to electromagnetic fields, labeled PEMFs, quite distinct from the $60 \mathrm{~Hz}$ electric and magnetic fields previously examined in the Canada-France study of utility workers $^{5}$ and in the United States cohort mortality study of utility workers. ${ }^{6}$ Short duration, intense fields are of interest largely because they have greater plausibility for producing adverse biological effects based on theoretical calculations and experimental evidence ${ }^{78}$ compared with the power frequency fields that have been more extensively studied.

In the analysis of PEMFs among workers at Hydro-Québec and Electricité de France, ${ }^{3}$ the positron meter was used to measure the proportion of time (measured in parts per billion) during which the electric field was $>200$ $\mathrm{V} / \mathrm{m}$ in the $5-20 \mathrm{MHz}$ frequency range. ${ }^{9}$ Little evidence was found to support an association between this index of PEMFs and most cancers, including leukaemia and brain cancer, yet lung cancer was found to be strongly associated with this exposure. The results were fairly consistent across the different measures of exposure, although the association was limited to workers at Hydro-Québec and was not apparent among the far less exposed employees at Électricité de France. Among workers at Hydro-Québec, PEMFs above the median generated an odds ratio of 2.4 (95\% confidence interval (95\% CI) 1.1 to 5.3 ) after adjustment for potential confounding factors. Among all workers, scores above the 90th percentile were associated with an odds ratio of 3.1 (95\% CI 1.6 to 6.0 ), with a dose-response gradient across levels of exposure. 
The availability of data from a large cohort mortality study of United States utility workers ${ }^{6}$ provided an opportunity to evaluate the consistency of these results, to a limited degree, rapidly and inexpensively. Two limitations on our ability to assess those findings should be noted at the outset. (1) We did not attempt to measure PEMFs directly, so that we can only make comparisons based on job groups or under rather tenuous assumptions that the groups of workers in the United States utilities have scores similar to workers at Hydro-Québec. (2) The meaning of the exposure data generated for PEMFs by the positron meter has been called into question because the meter seems to respond to fields of much higher frequency than desired, including those in the range of mobile telephones and two way radios used in motor vehicles. ${ }^{10-12}$ This problem does not negate or explain the previous findings, but it does leave serious uncertainties about what exposure has been identified and the sources of this measured exposure in the environment of electrical utility work. In the absence of other studies on lung cancer among electrical utility workers in the near future, we have chosen to comprehensively examine the evidence for lung cancer from the United States study of utility workers, including both $60 \mathrm{~Hz}$ magnetic fields and estimates of PEMFs. We considered individual jobs associated with increased exposure to $60 \mathrm{~Hz}$ magnetic fields in our assessment and jobs associated with relatively high PEMFs based on the Hydro-Québec study, as well as indices of $60 \mathrm{~Hz}$ magnetic fields based on our measurements and PEMFs based on extrapolation from the Hydro-Québec study.

\section{Methods}

Details of the study methods have been published elsewhere ${ }^{6}$ and are briefly summarised here. Eligibility for the cohort was limited to male employees at one of five participating electrical utility companies (Carolina Power and Light Company, Virginia Electric Power Company, PECO Energy Company, Tennessee Valley Authority, and Pacific Gas and Electric Company) who were employed full time at some time between 1950 and 1986, had six months continuous employment, and had not worked exclusively in the nuclear division of their companies. After exclusions due to lack of availability of records before 1 September 1954 and 1 January 1955 at two of the companies, missing date of birth $(n=51)$, unknown start dates $(n=30)$, and other errors in the records $(n=10), 138905$ eligible workers were included in the cohort.

Mortality follow up was required for the 76934 men who had retired, left, or ended employment by the cut off date of 31 December 1988. The National Death Index was relied on for workers who finished work in 1979 or later, or for workers with clear evidence of having survived to at least that time. Follow up for the earlier periods was based on Social Security Administration death benefit records, Health Care Financing Administration files, drivers' licence records, credit applications, telephone tracing, and vital record searches in individual states. The result of this effort was the identification of 55423 living cohort members, 20733 dead, and 778 lost to follow up. Death certificates were sought for all those who had died, and 20068 were obtained and coded according to the international classification of diseases, ninth revision (ICD-9). ${ }^{13}$

Job titles were grouped into 28 categories for assignment of exposure, with aggregation based on work activities and responsibilities, and secondarily, on potential exposure. ${ }^{14}$ Personal exposure to $60 \mathrm{~Hz}$ magnetic fields was measured with an AMEX meter ${ }^{15}$ for a full work shift on randomly selected workers, to assign exposure levels to the occupational category. ${ }^{16}$ The sampling was based on the estimated person-years contributed by occupation at each of the companies and on the presumed exposure level, with oversampling of workers presumed to have high and medium as opposed to low exposure (5:3:1 ratio). The 4094 attempted measurements resulted in 2842 usable measurements, with most losses due to workers' absence, procedural errors, failure to meet calibration criteria, or worker refusal. The measurement data were used to construct a job exposure matrix based on an analysis of variance to compare within and between group variability. ${ }^{17}$ Individual company and occupational category cells were rank ordered and grouped to maximise precision and between group variability. The resulting five groups had arithmetic mean exposure scores of $0.12,0.21,0.39,0.62$, and $1.27 \mu \mathrm{T}$, which were assigned to all person-years in the component occupational categories.

Potential exposures to PEMFs (or the entity measured by the positron meter in the HydroQuébec study) were estimated exclusively by extrapolation based on the assumption that groups of United States utility workers engaged in comparable work activities would have the same scores as workers at Hydro-Québec. The job exposure matrix in the published manuscript ${ }^{3}$ was supplemented with additional data on the remainder of job groups considered. Because of differences in the job grouping methods in the United States and CanadaFrance studies of utility workers, mapping the roster of 28 occupational categories to the 31 rows of the Hydro-Québec job exposure matrix was not straightforward. Initial assignments were made with detailed descriptions of the occupational categories and jobs, with a focus on the tasks and work environment. Further consultation with industrial hygienists involved with the development of each of the original job exposure matrices served to refine the assignments. Some occupational categories in the United States study of utility workers corresponded to several jobs in the HydroQuébec study, such as "linemen" in the United States study mapped to a composite of "all linemen", "emergency men", "distribution splicer", and "tree trimmer". In such instances, a weighted average score for the relevant Hydro-Québec jobs was computed based on the distribution of people measured for the Hydro-Québec categories. Conversely, some 
jobs in the Hydro-Québec study related to several occupational categories, such as "blue collar-generic" which corresponded to the United States utility study categories of "pipe coverers", "materials handlers", and "laborers". In those cases, the Hydro-Québec score was assigned to each of the component occupational groups. Because of the uncertainties that arose in the course of this effort, we also examined exposure assignments in broader categories of high, moderate, and background levels (defined below).

In the Hydro-Québec study, measurements of the exposure to PEMFs associated with specific jobs were used to construct a job exposure matrix, which was then applied to the study of cancer, as described in detail elsewhere. ${ }^{3}$ Briefly, measurements assessed the proportion of time (in parts per billion) during which high frequency electric fields were $>200 \mathrm{~V} / \mathrm{m}$. Because the distribution of exposure was highly skewed within job groups, the summary index chosen was the proportion of workers in each job group who had weekly mean exposure scores of $>100$ parts per billion (ppb), an arbitrary cut off point, but one that generated results which were consistent with other possible cut off points examined. The assignment of these indices (proportion of workers with over $100 \mathrm{ppb}$ ) was made for the United States utility occupational categories with the exact value assigned at Hydro-Québec. However, because of the substantial uncertainty in making that extrapolation, we also examined cancer mortality in relation to duration in high exposure jobs (jobs in which the proportion of workers above the $100 \mathrm{ppb}$ threshold exceeded $60 \%$ ) and moderate exposure jobs (jobs in which the proportion above the $100 \mathrm{ppb}$ threshold ranged from $25 \%$ to $60 \%$ ) relative to those jobs in which the proportion above the $100 \mathrm{ppb}$ threshold was $<25 \%$. High exposure jobs were supervisors, linemen, and cable splicers, moderate exposure jobs were mechanics, machinists, electricians, telecommunications technicians, and substation operators, and the rest were categorised as low exposure.

The same occupational categories served as the units for assignment of exposure to potentially confounding chemical agents. Panels of experts were convened at each of the participating companies and judgments were made about the potential for exposure to solvents, polychlorinated biphenyls, sunlight, and herbicides. For the purposes of the present analysis, a judgment had to be made on potential exposure to asbestos in this industry; it was not feasible to assess exposure to other potential lung carcinogens. Based on consultation with an industrial hygienist who participated in the original confounder assessment and conducted several on site evaluations, we assigned potential asbestos exposure to the job categories of mechanic, machinist, boilermaker, electrician, cable splicer, pipe coverer, and welder. The variable used for adjustment was the total number of years in these jobs (on average) with a 10 year lag period to account for a minimum disease latency after exposure.
DATA ANALYSIS METHODS

Standardised mortality ratios (SMRs) were calculated with the National Institute for Occupational Safety and Health life table analysis system to compare mortality in the total cohort with that of the United States male population, with indirect adjustment for age and calendar time.$^{18}$ Our primary interest was to compare subsets of the cohort defined by work history and supposed exposure to $60 \mathrm{~Hz}$ magnetic fields and PEMFs. Poisson regression $^{19}$ was used to generate adjusted mortality rate ratios comparing more exposed with less exposed workers, after adjustment for potential confounding factors.

We first examined mortality associated with duration of employment in jobs thought to have above background exposure to $60 \mathrm{~Hz}$ magnetic fields for individual jobs of lineman, electrician, and power plant operator and together. The control category consisted of person-years without experience in any of the exposed jobs. An index of cumulative exposure to magnetic field expressed in units of $\mu \mathrm{T}$-years was also calculated, as described in detail elsewhere. ${ }^{6}$ Briefly, the exposure associated with each job was assigned to each person-year of experience specific to the time windows of interest: total exposure with a lag of 2, 2-10, 10 to 20 , and $\geqslant 20$ years past. To select categories for analysis, we computed the exposure of all the workers who had died (separately for the four time windows) and established cut off points at each of the deciles of the distribution based on a rank ordering of the dead workers. Then, for the total exposure with a two year lag, the control group was $<30$ th percentile, and the other groups were defined as $30-<50$, $50-<70,70-<90$, and $\geqslant 90$ th percentile. For the other time windows, the control group had no exposure in the window and the other categories were $0-<30,30-<60,60-<80$, and $\geqslant 80$ th percentile.

Analogous procedures were followed for the examination of PEMFs. Jobs thought to have high exposure and moderate exposure were examined by calculating mortality rate ratios for duration of employment in those categories, each contrasted with person-years in jobs in which $<25 \%$ of workers exceeded the $100 \mathrm{ppb}$ time threshold. Also, linemen, cable splicers, and supervisors were evaluated individually, each was contrasted with person-years in low exposure jobs. An index of cumulative exposure to PEMFs was calculated that is analogous to the index for $60 \mathrm{~Hz}$ magnetic fields, with the same time windows, the same derivation of cut off points, and the same percentile categories for analysis. The units were derived as the proportion of workers in the job group exceeding the $100 \mathrm{ppb}$ time threshold and the duration of work in each job, expressed in units of "proportion $>100$ ppb-years."

All Poisson regression analyses included the same set of covariates: age (in five-year groups, smoothed to fit a $\log$-log relation with lung cancer mortality), calendar time (categorical variable, in decades), race (white, non-white), social class (upper white collar, lower white collar, skilled blue collar, unskilled blue collar), 
Table 1 Lung cancer SMRs: study of mortality in US utility workers 1950-88

\begin{tabular}{|c|c|c|c|}
\hline & Lung cancer deaths & Expected deaths & $S M R(95 \% C I)$ \\
\hline Total cohort & 1692 & 1859.5 & $0.91(0.87$ to 0.95$)$ \\
\hline \multicolumn{4}{|l|}{ Race: } \\
\hline White & 1391 & 1674.7 & $0.83(0.79$ to 0.88$)$ \\
\hline Non-white & 301 & 184.8 & $1.63(1.45$ to 1.82$)$ \\
\hline \multicolumn{4}{|l|}{ Social class: } \\
\hline Upper white & 131 & 239.7 & 0.55 (0.46 to 0.65$)$ \\
\hline Lower white & 210 & 267.2 & 0.79 (0.68 to 0.90$)$ \\
\hline Skilled blue & 798 & 798.2 & $1.00(0.93$ to 1.07$)$ \\
\hline Unskilled blue & 553 & 553.1 & $1.00(0.92$ to 1.09$)$ \\
\hline
\end{tabular}

Table 2 Lung cancer mortality by duration of employment in selected occupations with high $60 \mathrm{~Hz}$ magnetic fields

\begin{tabular}{lll}
\hline Exposure & Cases (n) & $R R$ (95\% CI) \\
\hline $\begin{array}{ll}\text { Duration in exposed occupations (y): } \\
0^{\star}\end{array}$ & 515 & $1.00-$ \\
$>0-<10$ & 396 & $1.05(0.90$ to 1.22$)$ \\
$10-<20$ & 356 & $1.31(1.11$ to 1.54$)$ \\
$\geqslant 20$ & 419 & $1.01(0.96$ to 1.35$)$ \\
Duration as a lineman: & & \\
$0^{\star}$ & 515 & $1.00-$ \\
$>0-<10$ & 119 & $1.15(0.90$ to 1.47$)$ \\
$10-<20$ & 71 & $1.13(0.85$ to 1.50$)$ \\
$\geqslant 20$ & 67 & $1.09(0.82$ to 1.45$)$ \\
Duration as an electrician: $\dagger$ & & \\
$0^{\star}$ & 515 & $1.00-$ \\
$>0-<10$ & 56 & $0.94(0.69$ to 1.29$)$ \\
$10-<20$ & 40 & $1.19(0.84$ to 1.70$)$ \\
$\geqslant 20$ & 39 & $1.38(0.97$ to 1.95$)$ \\
Duration as a power plant operator: & & \\
$0^{\star}$ & 515 & $1.00-$ \\
$>0-<10$ & 91 & $1.16(0.90$ to 1.51$)$ \\
$10-<20$ & 53 & $1.23(0.89$ to 1.69$)$ \\
$\geqslant 20$ & 57 & $1.43(1.05$ to 1.96$)$ \\
\hline
\end{tabular}

$\mathrm{RR}=$ rate ratio (adjusted for age, calendar year, race, social class, work status, and exposure to lung carcinogens).

* Control category is person-years with no exposure to any of the exposed occupational categories, the same for each exposure group.

t Exposure to lung carcinogens was redefined for this analysis to exclude electricians from the set of exposed occupations to avoid zero marginal cells.

active versus inactive work status (with a two year lag), and years of exposure to occupational lung carcinogens $(0,0-<5,5-<10,10-<20$, $\geqslant 20$ years in categories) with a 10 year lag as already described. Not all of these factors were found to operate as confounders in all analyses, but for convenience, all were included in the regression models. Data on tobacco use, a strong risk factor for lung cancer, were not available.

\section{Results}

Standardised mortality ratios comparing the entire cohort with the United States control population (table 1) showed a small reduction in total mortality from lung cancer but lower in magnitude than was found for total mortality (SMR 0.77) or for total cancer (SMR 0.86). ${ }^{6}$ The differences by race are striking, with an excess mortality from lung cancer among nonwhites, potentially attributable to a different mix of non-whites in the cohort compared with the United States population or some lifestyle or occupational hazard that is more common among minority workers. The gradient in SMRs by social class follows the expected pattern, with notable reductions among white collar workers (particularly in the upper classes) compared with blue collar workers.

Mortality from lung cancer did not show a clear pattern in relation to the duration of employment in jobs associated with increased exposure to a $60 \mathrm{~Hz}$ magnetic field (table 2).
Table 3 Lung cancer mortality relative to exposure to 60 $\mathrm{Hz}$ magnetic fields

\begin{tabular}{lll}
\hline Exposure & Cases $(n)$ & $R R(95 \%$ CI) \\
\hline $\begin{array}{l}\text { Total exposure }(\mu \mathrm{T}-\mathrm{y}): \\
0-0.59\end{array}$ & 412 & $1.00-$ \\
$0.59-1.14$ & 334 & $1.06(0.91$ to 1.23$)$ \\
$1.14-1.98$ & 376 & $1.09(0.94$ to 1.27$)$ \\
$1.98-4.28$ & 377 & $1.09(0.94$ to 1.27$)$ \\
$4.28-15.45$ & 187 & $1.09(0.89$ to 1.33$)$ \\
Past $2-10$ y: & & \\
0 & 597 & $1.00-$ \\
$>0-0.20$ & 271 & $1.07(0.92$ to 1.24$)$ \\
$0.20-0.39$ & 260 & $1.13(0.95$ to 1.34$)$ \\
$0.39-0.71$ & 256 & $1.26(1.05$ to 1.31$)$ \\
$0.71-2.35$ & 302 & $1.30(1.08$ to 1.57$)$ \\
Past $10-20$ y: & & \\
0 & 270 & $1.00-$ \\
$>0-0.28$ & 407 & $1.01(0.87$ to 1.18$)$ \\
$0.28-0.51$ & 359 & $1.15(0.98$ to 1.35$)$ \\
$0.51-0.89$ & 221 & $1.17(0.97$ to 1.40$)$ \\
$0.89-2.93$ & 429 & $1.21(1.03$ to 1.42$)$ \\
Past $>20$ y: & & \\
0 & 354 & $1.00-$ \\
$>0-0.39$ & 418 & $1.43(1.23$ to 1.67$)$ \\
$0.39-1.06$ & 402 & $1.32(1.12$ to 1.56$)$ \\
$1.06-2.03$ & 269 & $1.33(1.11$ to 1.60$)$ \\
$2.03-14.55$ & 243 & $1.25(1.02$ to 1.52$)$ \\
\hline
\end{tabular}

$\mathrm{RR}=$ rate ratio (adjusted for age, calendar year, race, social class, work status, and exposure to lung carcinogens).

Rate ratios were modestly increased in the $10-<20$ year interval but decreased for longer periods of employment in combined job exposures. Duration of work as a lineman had little impact on risk of lung cancer, whereas duration of work as an electrician or power plant operator was associated with a weak gradient of increasing rate ratios that peaked at around 1.4 in the interval with $\geqslant 20$ years of employment.

Risk of lung cancer was similarly very weakly associated with an index of exposure to a $60 \mathrm{~Hz}$ magnetic field (table 3 ). For total exposure over the work career with a two year lag, the rate ratios were around 1.1 for all categories above the control. For exposure windows of $2-<10$ years and $10-<20$ years, rate ratios rose modestly with increasing exposure scores, but reached only 1.3 and 1.2 , respectively, in the highest interval. For the longest latency window of $\geqslant 20$ years, rate ratios were increased above the control group but did not show a positive dose response gradient in relation to exposure. To find whether a more highly exposed subset might show a larger increase in risk, the upper category for the $2-<10$ year window was subdivided into $0.71-1.13 \mu \mathrm{T}$ years and 1.13-2.35 $\mu$ T-years, corresponding to the 80 th-90th percentile and the $\geqslant 90$ th percentile. The rate ratios for these categories were 1.39 (95\% CI 1.14 to 1.70$)$ and 1.14 (95\% CI 0.87 to 1.48 ), indicating a lack of notable increase for the most highly exposed group.

Table 4 shows analysis of individual and combined jobs associated with above background exposure to PEMFs. With a broad definition of exposed jobs as those in which $\geqslant 25 \%$ of the measurements exceeded the 100 $\mathrm{ppb}$ time threshold, the number of years in such occupations was not clearly related to lung cancer (or total cancer or total mortality), with person-years in jobs below that threshold as the control. For each cause of death grouping, the rate ratios rose in the middle categories to around 1.1 but fell in the category of $\geqslant 20$ 
Table 4 Mortality relative to duration of work in occupations exposed to PEMFs

\begin{tabular}{|c|c|c|c|c|c|c|}
\hline \multirow[b]{2}{*}{ Exposure } & \multicolumn{2}{|c|}{ Total mortality } & \multicolumn{2}{|c|}{ Cancer mortality } & \multicolumn{2}{|c|}{ Lung cancer mortality } \\
\hline & Cases (n) & $R R(95 \% C I)$ & Cases (n) & $R R(95 \% C I)$ & Cases (n) & $R R(95 \% C I)$ \\
\hline \multicolumn{7}{|c|}{ Years in exposed occupations: ${ }^{\star}$} \\
\hline $0 \dagger$ & 11829 & $1.00-$ & 2671 & $1.00-$ & 899 & $1.00-$ \\
\hline $1-<10$ & 4074 & $1.10(1.05$ to 1.14$)$ & 944 & $1.12(1.03$ to 1.23$)$ & 327 & $1.10(0.95$ to 1.27$)$ \\
\hline $10-<20$ & 2501 & $1.12(1.06$ to 1.18$)$ & 626 & 1.15 (1.04 to 1.28$)$ & 232 & $1.16(0.98$ to 1.37$)$ \\
\hline$\geqslant 20$ & 2329 & $1.05(0.99$ to 1.12$)$ & 592 & $1.04(0.93$ to 1.17$)$ & 228 & $1.05(0.87$ to 1.28$)$ \\
\hline \multicolumn{7}{|c|}{ Years in highly exposed occupations: } \\
\hline $0 \dagger$ & 11829 & $1.00-$ & 2671 & $1.00-$ & 899 & $1.00-$ \\
\hline $1-<10$ & 2866 & $1.10(1.05$ to 1.15$)$ & 670 & $1.12(1.02$ to 1.23$)$ & 240 & $1.12(0.95$ to 1.31$)$ \\
\hline $10-<20$ & 1612 & $1.11(1.05$ to 1.17$)$ & 400 & $1.12(1.00$ to 1.26$)$ & 149 & $1.17(0.96$ to 1.41$)$ \\
\hline$\geqslant 20$ & 1196 & $1.08(1.01$ to 1.15$)$ & 307 & $1.11(0.97$ to 1.26$)$ & 113 & $1.15(0.92$ to 1.43$)$ \\
\hline \multicolumn{7}{|c|}{ Years as a lineman: } \\
\hline $0+$ & 11829 & $1.00-$ & 2671 & $1.00-$ & 899 & $1.00-$ \\
\hline $1-<10$ & 1627 & 1.15 (1.09 to 1.22$)$ & 321 & $1.08(0.95$ to 1.23$)$ & 119 & $1.10(0.89$ to 1.35$)$ \\
\hline $10-<20$ & 839 & $1.12(1.04$ to 1.21$)$ & 189 & $1.06(0.91$ to 1.25$)$ & 71 & $1.10(0.85$ to 1.43$)$ \\
\hline$\geqslant 20$ & 758 & $1.11(1.02$ to 1.21$)$ & 196 & $1.13(0.95$ to 1.33$)$ & 67 & $1.09(0.82$ to 1.44$)$ \\
\hline \multicolumn{7}{|c|}{ Years as a cable splicer: } \\
\hline $0 \dagger$ & 11829 & $1.00-$ & 2671 & $1.00-$ & 899 & $1.00-$ \\
\hline $1-<10$ & 67 & $0.69(0.54$ to 0.89$)$ & 17 & $0.69(0.41$ to 1.14$)$ & 16 & $0.62(0.34$ to 1.11$)$ \\
\hline $10-<20$ & 56 & $1.11(0.83$ to 1.50$)$ & 16 & $1.20(0.68$ to 2.13$)$ & - & - \\
\hline$\geqslant 20$ & 49 & $0.78(0.56$ to 1.08$)$ & 15 & $0.95(0.51$ to 1.76$)$ & - & - \\
\hline \multicolumn{7}{|c|}{ Years as a supervisor: } \\
\hline of & 11829 & $1.00-$ & 2671 & $1.00-$ & 899 & $1.00-$ \\
\hline $1-<10$ & 1683 & $1.07(1.02$ to 1.14$)$ & 462 & $1.19(1.07$ to 1.33$)$ & 178 & $1.26(1.05$ to 1.51$)$ \\
\hline $10-<20$ & 812 & $1.01(0.93$ to 1.09$)$ & 218 & $1.08(0.93$ to 1.25$)$ & 78 & 1.08 (0.84 to 1.38$)$ \\
\hline$\geqslant 20$ & 300 & $0.99(0.88$ to 1.12$)$ & 78 & $1.04(0.82$ to 1.31$)$ & 32 & $1.20(0.84$ to 1.74$)$ \\
\hline
\end{tabular}

$\mathrm{RR}=$ rate ratio (adjusted for age, calendar year, race, social class, work status, and exposure to lung carcinogens).

$\star$ Exposed occupations include supervisors, linemen, cable splicers, mechanics, machinists, electricians, telecommunications technicians, and substation operators highly exposed occupations include supervisors, linemen, and cable splicers only.

† Control category is person-years with no exposure to any of exposed occupational categories, the same for each exposure group.

years of employment. When exposed jobs were restricted to those with $\geqslant 60 \%$ of measurements above the $100 \mathrm{ppb}$ threshold, the duration of work was associated with a rate ratio of around 1.1 for all categories above the control, similarly for total mortality, total cancer, and lung cancer. Number of years as a linemen, cable splicer, or supervisor did not show distinctive patterns.

Finally, cumulative exposure to PEMFs was constructed and evaluated relative to total mortality, cancer mortality, and lung cancer (table 5). For total exposure, mortality and total cancer showed rate ratios of 1.1 to 1.2 in the above background categories, whereas lung cancer had slightly higher rate ratios of 1.3 to 1.4 but little evidence for increasing risk across levels of increasing exposure. Examination of exposure in windows of $2-<10$ and $10-<20$ years enhanced this contrast, with overall mortality and cancer mortality showing little evidence of an association with increasing PEMF score, and lung cancer showing a weak positive gradient that only reached rate ratios of 1.3 in the highest interval. A latent period of 20 years generated a pattern of a small increased risk of lung cancer with exposure above the control group (rate ratios around 1.2) but no increase thereafter.

\section{Discussion}

Lung cancer was weakly associated with duration of work as an electrician or power plant operator as well as with cumulative PEMF

Table 5 Lung cancer mortality relative to cumulative exposures to PEMFs

\begin{tabular}{|c|c|c|c|c|c|c|}
\hline \multirow[b]{2}{*}{ Exposure } & \multicolumn{2}{|c|}{ Total mortality } & \multicolumn{2}{|c|}{ Cancer mortality } & \multicolumn{2}{|c|}{ Lung cancer mortality } \\
\hline & Cases (n) & $R R(95 \% C I)$ & Cases (n) & $R R(95 \% C I)$ & Cases (n) & $R R(95 \% C I)$ \\
\hline \multicolumn{7}{|l|}{ Total exposure: } \\
\hline $0-0.70$ & 6303 & $1.00-$ & 1357 & $1.00-$ & 404 & $1.00-$ \\
\hline $0.70-2.50$ & 3975 & $1.12(1.06$ to 1.17$)$ & 881 & 1.14 (1.03 to 1.27$)$ & 323 & $1.27(1.06$ to 1.51$)$ \\
\hline $2.50-5.40$ & 4239 & $1.15(1.09$ to 1.21$)$ & 988 & $1.15(1.03$ to 1.28$)$ & 362 & $1.25(1.04$ to 1.51$)$ \\
\hline $5.40-11.90$ & 4134 & $1.13(1.07$ to 1.19$)$ & 1087 & 1.21 (1.09 to 1.36$)$ & 401 & $1.32(1.09$ to 1.60 \\
\hline $11.90-41.15$ & 2082 & $1.18(1.10$ to 1.26$)$ & 520 & $1.19(1.04$ to 1.37$)$ & 196 & 1.35 (1.07 to 1.69 \\
\hline \multicolumn{7}{|l|}{ Past 2-10 y: } \\
\hline 0 & 11874 & $1.00-$ & 2673 & $1.00-$ & 856 & $1.00-$ \\
\hline$>0-0.70$ & 2582 & $0.96(0.91$ to 1.00$)$ & 565 & $1.01(0.92$ to 1.11$)$ & 202 & $1.07(0.91$ to 1.26$)$ \\
\hline $0.70-1.80$ & 2789 & $0.97(0.93$ to 1.02$)$ & 682 & $1.05(0.95$ to 1.15$)$ & 263 & $1.20(1.03$ to 1.41$)$ \\
\hline $1.80-3.00$ & 1736 & $0.94(0.89$ to 1.00$)$ & 446 & $0.99(0.88$ to 1.11$)$ & 176 & $1.14(0.94$ to 1.38$)$ \\
\hline $3.00-7.45$ & 1752 & $1.02(0.96$ to 1.08$)$ & 467 & $1.10(0.98$ to 1.23$)$ & 189 & 1.34 (1.11 to 1.62$)$ \\
\hline \multicolumn{7}{|l|}{ Past $10-20 \mathrm{y}$ : } \\
\hline 0 & 8532 & $1.00-$ & 1851 & $1.00-$ & 580 & $1.00-$ \\
\hline$>0-1.00$ & 3711 & $1.02(0.98$ to 1.07$)$ & 820 & $1.07(0.98$ to 1.17$)$ & 288 & $1.08(0.93$ to 1.26$)$ \\
\hline $1.00-2.30$ & 3746 & $1.05(1.01$ to 1.10$)$ & 920 & $1.12(1.02$ to 1.22$)$ & 331 & $1.15(0.99$ to 1.35$)$ \\
\hline $2.30-3.70$ & 2322 & $0.97(0.92$ to 1.02$)$ & 590 & $1.02(0.91$ to 1.14$)$ & 237 & $1.14(0.96$ to 1.37$)$ \\
\hline $3.70-9.31$ & 2422 & $1.04(0.99$ to 1.10$)$ & 652 & 1.15 (1.03 to 1.27$)$ & 250 & $1.27(1.07$ to 1.51$)$ \\
\hline \multicolumn{7}{|l|}{ Past $>20 \mathrm{y}:$} \\
\hline 0 & 8577 & $1.00-$ & 1803 & $1.00-$ & 562 & $1.00-$ \\
\hline$>0-1.10$ & 3590 & $1.05(1.01$ to 1.10$)$ & 904 & $1.12(1.03$ to 1.23$)$ & 327 & $1.22(1.05$ to 1.43$)$ \\
\hline $1.10-3.30$ & 3763 & $1.05(1.00$ to 1.10$)$ & 946 & $1.08(0.97$ to 1.19$)$ & 367 & 1.25 (1.06 to 1.48 \\
\hline $3.30-6.30$ & 2375 & $1.05(0.99$ to 1.12$)$ & 601 & $1.08(0.96$ to 1.22$)$ & 234 & $1.26(1.04$ to 1.54$)$ \\
\hline $6.30-39.38$ & 2428 & $1.14(1.07$ to 1.21$)$ & 579 & $1.15(1.01$ to 1.31$)$ & 196 & $1.17(0.94$ to 1.46$)$ \\
\hline
\end{tabular}


score above the control category. The largest rate ratios found were $1.3-1.4$, precise but modest in magnitude. Lung cancer was not associated with duration of work as a lineman or with totol jobs thought to have high exposure to $60 \mathrm{~Hz}$ or PEMFs. Indices of total exposure to $60 \mathrm{~Hz}$ magnetic fields were not associated with risk of lung cancer, and very small associations (rate ratios of 1.1 to 1.4) were found for exposure in specific time windows but without positive trends of increasing risk with increasing exposure.

Relative to the limited information on PEMFs, the available data on $60 \mathrm{~Hz}$ magnetic fields is of sufficient quality to conclude that average exposure to magnetic fields show little or no association with mortality from lung cancer in our population. There are clear limitations inherent in the construction of the job exposure matrix, which requires grouping potentially heterogeneous jobs, generalising for all people based on a random sample of workers, and assuming that present day measurements have applicability to the same jobs in the past. None the less, although the quantitative measures are subject to error, there is sufficient predictability of exposure in this industry to suggest that long duration of employment in exposed jobs such as electrician and lineman is a valid marker of increased cumulative exposure over that period. We cannot extrapolate this lack of association with $60 \mathrm{~Hz}$ magnetic fields to other possible indices of exposure to $60 \mathrm{~Hz}$ such as electrical fields or other variables of magnetic fields such as peaks or excursions in and out of high fields.

Our evaluation of PEMFs was much more tenuous, relying on measurements from another study. There is substantial uncertainty about precisely what physical exposure sources were reflected in the original PEMF measurements given the wide frequency range captured by the positron meter. ${ }^{10-12}$ The effort to export the job exposure matrix from Hydro-Québec to the United States utility companies required matching job groups, with some loss of information as a result. Additional attenuation in the accuracy of estimation would result from the assumption that workers engaged in broadly similar jobs would have similar PEMF scores. The specific characteristics of HydroQuébec-such as the methods of generating electric power or methods of work organisation -could make extrapolation more problematic than for $60 \mathrm{~Hz}$ magnetic fields, for which the determinants of exposure are much better understood. The high PEMF score for supervisors, for example, is somewhat counterintuitive, but the combined group "foremen" from Hydro-Québec, the closest counterpart to "supervisors," which consisted of field, craft, and trade supervisors in our study rather than white collar managers, gave nine of 14 measurements $>100 \mathrm{ppb}$. The potential for interference from other sources could account for this pattern. ${ }^{11}$ Without a clear understanding of the source and implications of exposures to PEMFs, ${ }^{12}$ we are not able to objectively evaluate the validity of our extrapolation. Especially in the presence of such uncertainty about the physical variables of interest, the most direct way to assess the replicability of the Hydro-Québec findings would be to collect comparable measurements of PEMFs and assess the relation of such measurements to risk of lung cancer.

The pattern of results, in which very weak associations were found (rate ratios of $\leqslant 1.4$ ) leaves us with two possibilities: the measured association between PEMFs and lung cancer in the United States utility companies would be similar in size to that found among workers at Hydro-Québec if it were not for measurement error resulting from application of a job exposure matrix generated on other workers; or our data accurately indicate that there is little or no association between presumed exposures to PEMFs and lung cancer, with the residual association due to confounding or other biases. Analyses of a cruder measure of exposure to PEMFs in the Hydro-Québec study, based on years in exposed job categories, gave evidence of an increased risk of lung cancer that was diluted relative to the results from the actual PEMF exposure scores. Even analyses of linemen alone gave increased risks of lung cancer: for $\geqslant 10$ years as a lineman, the odds ratio with adjustment for socioeconomic status but not cigarette smoking was 2.03 (95\% CI 1.14 to 3.62). Thus, even with a cruder form of exposure to PEMFs, the Hydro-Québec cohort gave notably stronger associations with lung cancer than were found in the United States study of utility workers. However, if the suggestion from the Hydro-Québec analysis is to be more firmly corroborated or refuted, a clear understanding of the nature of the measured exposures to PEMFs is needed.

In contrast to earlier analyses of leukaemia and brain cancer, in which strong confounders were difficult to specify, in the analysis of lung cancer there were clear and plausible candidates for confounding. Data on cigarette smoking were not available and thus could not be taken into account in the analysis. Anecdotal observations suggest that some groups of utility workers have tended to be heavy smokers, but these impressions relate largely to the distinctions we attempted to capture with our measure of social class. The distinct gradient in risk of lung cancer that was identified in relation to social class, with notably reduced risks for white collar compared with blue collar workers gives some assurance that we have captured lifestyle determinants of lung cancer such as tobacco use or possibly dietary factors. By adjusting for social class, some of the potential confounding influence should have been removed. However, given the strength of the association between tobacco use and lung cancer, it is conceivable that risk ratios in the order of 1.3 to 1.4 would be a result of such confounding. ${ }^{20}$

We also attempted to consider occupational exposures to asbestos, which is known to be associated with lung cancer. ${ }^{21}$ We created an indicator of the duration of work in a combination of jobs with some potential for exposure, with a 10 year lag, and adjusted for this variable. Because of the original focus on associations 
with leukaemia and brain cancer, we did not collect detailed information on potential exposure to agents such as asbestos, so that the adjustment may have been incomplete. As expected, the index that we examined showed a positive association with lung cancer, particularly in the highest category of $\geqslant 20$ years exposure. However, the magnitudes of the rate ratios were modest, never exceeding 1.5 in the highest interval, suggesting that if asbestos is more strongly related to lung cancer in this industry, not known at present, we were not able to identify and fully adjust for that association.

Combined with the results from the CanadaFrance study, ${ }^{5}$ there is little support for an association between $60 \mathrm{~Hz}$ magnetic fields and lung cancer. Despite the evidence that some previous studies of residential and occupational exposure to $60 \mathrm{~Hz}$ electric and magnetic fields have found associations with lung cancer, ${ }^{22}$ the two largest analyses of utility workers provide little or no support for such an association. The single clear indication of an association with PEMFs, ${ }^{3}$ combined with a lack of supportive experimental evidence, the uncertainties resulting from the meter characteristics, and the lack of support based on the limited data provided by the present study leaves unresolved the question of whether some aspect of high frequency electromagnetic fields are associated with lung cancer. A clarification of the hypothesised physical variable of interest is needed for further epidemiological studies to be of value.

We acknowledge the substantial contribution to the study and analysis of the following people: colleagues from the University of North Carolina Drs Michael Flynn, Lawrence Kupper, Dany Loomis, Stephen Rappaport, and Lori Todd, Dr, Dan Loomis, Stepher erlands; research assistants Dr Stephen Browning, Kevin Chen, erlands; research assistants Dr Stephen Browning, Kevin Chen,
Gary Mihlan, Dr Lucy Peipins, and Sandy West; computer proGary Mihlan, Dr Lucy Peipins, and Sandy West; computer programmers Dr Robert Kleckner, Richard Howard, Eileen Gregory, and Joy Wood; Electric Power Research Institute project officers Robert Black and Dr Leeka Kheifets, and Dr Kristie Ebi; EPRI scientific advisors Drs AA Afif, Patricia Buffler, and James Quackenboss; and collaborating contractors J Michael Silva and Richard Iriye of Enertech Consultants, Dr William Kaune of EM Factors, Dr Margaret Pennybacker of Battelle - Survey Research Associates, Judy Rayner of Westat, and William West. As well as those people mentioned individually, many electrical utility employees from Carolina Power and Light, Pacific Gas and Electric, PECO Energy Company (formerly Philadelphia Electric Company), Tennessee Valley Authority, and Virginia Electric Power Company, devoted much time to assisting us with many aspects of the study, lending their expertise, time, and patience, for which we are most expertise, time, and patience, for which we are most
appreciative. Also, we acknowledge the assistance of Dr Michel appreciative. Also, we acknowledge the assistance of Dr Michel Plante of Hydro-Québec for allowing us to use the data on exposure to PEMFs for this analysis and Jan Deadman of Hyrdo-Québec with those of United States utility workers.

1 Thériault GP. Health effects of electromagnetic radiation on workers: epidemiologic studies. In: Bierbaum PE, JM, eds. Proceedings of the scientific workshop on the health effects of electric and magnetic fields on workers. Cincinnati, OH. National Institute for Occupational Safety and Health, OH: National Institute for Occupational Safety and

2 Savitz DA, Ahlbom A. Epidemiologic evidence on cancer in relation to residential and occupational exposures. In: Carpenter DO, Ayrapetyan S, eds. Biological effects of electric and magnetic fields, Vol II. San Diego: Academic Press, 1994;233-61.

3 Armstrong B, Thériault G, Guenel P, Deadman J, Goldberg $M$, Heroux P. Association between exposure to pulsed electromagnetic fields and cancer in electric utility workers in tromagnetic fields and cancer in electric utility workers in Québec,

4 Horm JW, Asire AJ, Young JL Jr, Pollack ES, eds. SEER program: cancer incidence and mortality in the United States, 1973-81. Bethesda, MD: US Department of Health and Human Services, Public Health Service. National Cance Institute, 1984. (NIH Publ No 85-1847.)

5 Thériault G, Goldberg M, Miller AB, Armstrong B, Guénel $\mathrm{P}$, Deadman J, et al. Cancer risks associated with occupational exposure to magnetic fields among electric utility workers in Ontario and Québec, Canada, and France: 1970-89. Am $\Im$ Epidemiol 1994;139:550-72.

6 Savitz DA, Loomis DP. Magnetic field exposure in relation to leukemia and brain cancer mortality among electric utility workers. Am $\mathcal{F}$ Epidemiol 1995;141:123-34.

7 Skyberg K, Hansteen IL, Vistnes AI. Chromosome aberrations in lymphocytes of high-voltage laboratory cable splicers exposed to electromagnetic fields. Scand $\mathcal{F}$ Work Environ Health 1993;19:29-34.

8 Takahashi K, Kaneko I, Date M, et al. Effect of pulsing electromagnetic fields on DNA synthesis in mammalian cells in culture. Experientia 1986;42:185-6.

9 Heroux P. A dosimeter for assessment of exposure to ELF fields. Bioelectromagnetics 1991;12:241-57.

10 Maruvada PS, Jutras P. Identification of sources responsible for utility worker exposure data obtained using Positron HFT channel. Vareness, Québec, Canada: Institut de recherche d'hydro-Québec (IREQ), 1994. Report IREQ-94-242C.

11 ENERTECH Consultants. Frequency response characterization of the Positron electromagnetic dosimeter pulsed electromagnetic field/high-frequency transient electric field channel. Campbell, CA: ENERTECH Consultants, 1994. (RP 2966-07, Interim Report.)

12 Skotte JH. Exposure to high frequency transient electromagnetic fields. Scand $\mathcal{F}$ Work Environ Health 1996;22:39 44.

13 US Health Care Financing Administration. Commission on professional and hospital activities. International classification of diseases, 9 th revision, clinical modification, 2 nd ed. Washing ton, DC: US GPO, 1980. (DHHS Publ No (PHS) 80-1260).

14 Loomis DP, Peipins LA, Browning SR, Howard RL, Savitz DA. Organization and classification of work history data in industry-wide studies: an application to the electric power industry. Am F Ind Med 1994;26:413-25.

15 Kaune WT, Niple JC, Liu MJ, et al. Small integrating meter for assessing long-term exposure to magnetic fields. Bioelectromagnetics 1992;13:413-27.

16 Loomis DP, Kromhout H, Peipins LA, Kleckner RC, Iriye $R$, Savitz DA. Sampling design and field methods of a large, randomized multi-site survey of occupational magnetic field exposure. Appl Occup Environ Hyg 1994;9:49-52.

17 Kromhout H, Loomis DP, Mihlan GJ, Peipins LA, Kleckner Kromhout H, Loomis DP, Mihlan GJ, Peipins LA, Kleckner
RC, Iriye R, Savitz DA. Assessment and grouping of occupational magnetic field exposure in five electric utility companies. Scand $\mathcal{F}$ Work Environ Health 1995;21:43-50.

18 Steenland K, Beaumont J, Spaeth S, Brown D, Okun A, Jurcenko L, et al. New developments in the life table analysis system of the National Institute for Occupational Safety and Health. F Occup Med 1990;32:1091-8.

19 Frome EL, Checkoway H. Use of Poisson regression models in estimating incidence rates and ratios. Am $\mathcal{F}$ Epidemiol 1985;121:309-23.

20 Axelson $\mathrm{O}$, Steenland $\mathrm{K}$. Indirect methods of assessing the effects of tobacco use in occupational studies. $A m \mathcal{F}$ Ind Med 1988;13:105-18.

21 Selikoff IJ, Hammond ED, Churg J. Asbestos exposure, smoking and neoplasia. $\mathscr{f} A M A$ 1968;204:106-12.

22 Erren TC. Re: association between exposure to pulsed electromagnetic fields and cancer in electric utility workers in Québec, Canada and France [letter]. Am $\mathcal{F}$ Epidemiol 1996, 143:841. 